\title{
ANALISIS KEPUASAN MUSTAHIQ TERHADAP KUALITAS PELAYANAN DENGAN METODE IMPORTANCE PERFORMANCE ANALYSIS (IPA) (STUDI KASUS PADA BAITUL MAL)
}

\author{
Anwar \\ Dosen Jurusan Teknik Industri \\ Fakultas Teknik, Universitas Malikussaleh \\ Jl. Batam No.3 Komp.Bukit Indah Lhokseumawe - Aceh 24353 \\ anwar_muhammadali@yahoo.co.id
}

\begin{abstract}
Abstrak. Baitul Mal is a social institution, which is engaged in charity of zakat fund raising for the sake of socially patterned and sustainable. In its service Baitul Mal must be prosecuted to prioritize satisfaction of mustahiq, so that progress in the quality of service and able to improve the mustahiq economy and also giving a positive impact on the survival of Baitul Mal. The existing service is not yet known about the satisfaction that has been felt by the community, for it needs to be done research on the quality of service at Baitul Mal Kota Lhokseumawe. In this research used approach using Importance Performance Analysis (IPA) and Kano model. The purpose of this research is to know the priority of attributes that must be improved in accordance with the wishes mustahiq. The result indicates that, these methods allow us to know the priority attributes that must be improved its performance by the Baitul Mal it is the Amil of Baitul Mal Kota Lhokseumawe act based on islamic morality, Amil Baitul Mal Kota Lhokseumawe solve the mustahiq problem related to zakat program on time, Baitul Mal Kota Lhokseumawe always serve mustahiq effectively, Amil Baitul Mal Kota Lhokseumawe has knowledge about zakat, the Zakat given by Baitul Mal Kota Lhokseumawe has fulfilled the necessity of mustahiq, Zakat given by Baitul Mal Kota Lhokseumawe can improve the prosperity of mustahiq and Amil Baitul Mal Kota Lhokseumawe do not distinguish between mustahiq one and others.
\end{abstract}

Keywords: Importance Performance Analysis (IPA), Mustahiq Satisfaction, Service Quality, Kano Model

\begin{abstract}
Abstrak. Baitul Mal merupakan lembaga sosial, yang bergerak dalam penggalangan dana zakat untuk kepentingan sosial secara terpola dan berkesinambungan. Dalam pelayanannya Baitul Mal harus dituntut untuk mengedepankan kepuasan mustahiq, sehingga terjadi kemajuan dalam kualitas pelayanan dan mampu mengangkat perekonomian mustahiq serta akan memberikan dampak positif terhadap kelangsungan Baitul Mal. Pelayanan yang ada saat ini belum diketahui tentang kepuasan yang telah dirasakan oleh masyarakat, untuk itu perlu dilakukan penelitian tentang kualitas pelayanan pada Baitul Mal Kota Lhokseumawe. Dalam Penelitian ini digunakan pendekatan menggunakan metode Importance Performance Analysis (IPA) dan model Kano. Penelitian ini dilakukan bertujuan untuk dapat mengetahui prioritas atribut yang harus diperbaiki sesuai dengan keinginan mustahiq. Dari hasil penggunaan metode tersebut dapat diketahui prioritas atribut yang harus ditingkatkan kinerjanya oleh pihak Baitul Mal yaitu Amil Baitul Mal Kota Lhokseumawe dalam menyelesaikan masalah mustahiq terkait program zakat tepat waktu, Amil Baitul Mal Kota Lhokseumawe dapat menjelaskan informasi kepada mustahiq dengan jelas, Amil Baitul Mal Kota Lhokseumawe memiliki pengetahuan tentang zakat, zakat yang diberikan Baitul Mal kota Lhokseumawe telah memenuhi kebutuhan pokok mustahiq, dan zakat yang diberikan Baitul Mal kota Lhokseumawe mampu meningkatkan kesejahteraan mustahiq.
\end{abstract}

Kata Kunci: Importance Performance Analysis (IPA), Kepuasan Mustahiq, Kualitas Pelayanan, Model Kano

\section{Pendahuluan}

Baitul Mal merupakan lembaga sosial dalam penggalangan dana zakat, pelayanan pada Baitul Mal merupakan hal yang sangat penting untuk diperhatikan. Pelayanan yang baik akan memberikan kepuasan tersendiri terhadap mustahiq. Dalam jurnal yang ditulis oleh Heru dkk, Kepuasan pelanggan adalah pertahanan paling baik melawan persaingan bisnis. Perusahaan yang berhasil menjaga agar pelanggannya selalu puas hampir tidak terkalahkan dalam bisnis. Dalam jurnal yang ditulis oleh Naily dikutip dalam (Supranto, 2006) Tingkat kepuasan merupakan fungsi dari perbedaan kinerja yang dirasakan dengan harapan, apabila kinerja dibawah harapan, pelanggan akan kecewa tetapi bila kinerja sesaui dengan harapan, pelanggan akan puas. Sedangkan dalam jurnal yang ditulis oleh Lulu dkk, metode lain yang dapat digunakan untuk menyelesaikan permasalahan kepuasan 
konsumen metode Customer Satisfaction Index (CSI).

Dalam mewujudkan kepuasan mustahiq dibutuhkan kualitas pelayanan sebaik mungkin serta komitmen yang tinggi dari para amil, sebab mustahiq merupakan target utama dalam pendistribusian zakat serta mampu mensejahterakan kehidupan para mustahiq menjadi lebih baik. Untuk itu, perlu dilakukan penelitian pada Baitul Mal mengenai kepuasan mustahiq terhadap kualitas pelayanan yang diberikan. Karena kepuasan mustahiq akan banyak memberikan dampak positif bagi kelangsungan Baitul Mal.

\section{Tujuan Penelitian}

Adapun tujuan dari penelitian ini adalah untuk mengetahui atribut-atribut apa saja yang menjadi prioritas utama dalam kualitas pelayanan di Baitul Mal Kota Lhokseumawe.

\section{Manfaat Penelitian}

Manfaat yang diharapkan dapat diperoleh dari penelitian ini, antara lain:

1. Dapat membantu dalam memperbaiki kualitas pelayanan yang telah diterapkan sebelumnya.

2. Memberikan wawasan atau informasi mengenai kondisi kepuasan mustahiq terhadap kualitas pelayanan.

\section{Tinjauan Pustaka}

\subsection{Pengertian Zakat}

Ditinjau dari segi bahasa, zakat memiliki beberapa arti, yaitu al-barakatu (keberkahan), alnama (pertumbuhan dan perkembangan), al-tharatu (kesucian) dan al-salahu (kebaikan) (Majma, 1972).

Ditinjau dari segi fikih, zakat merupakan sejumlah harta yang diwajibkan Allah untuk diserahkan kepada yang berhak. Zakat adalah bagian dari harta dengan persyaratan tertentu yang diwajibkan oleh Allah SWT, untuk diserahkan kepada yang berhak menerimanya, dengan persyaratan tertentu (Mulyani, 2008).

Zakat adalah ibadah māliyah ijtimā'iyyah yang memiliki kedudukan yang penting, strategik dan menentukan, dari sudut ajaran maupun pembangunan kesejahteraan umat (Yūsuf Qaraḍāwī, 1993). Zakat termasuk dalam rukun Islam, sehingga dianggap ma'lum minad-din bi aldarurah (diketahui secara automatik adanya) dan merupakan bagian mutlak dari keislaman seseorang (Ali Yafie, 1994). Bahkan dalam Al-Qur'an juga terdapat ayat-ayat yang menyamakan taraf sholat dan kewajiban zakat.
Terdapat nas Al-Qura'an tentang zakat dalam istilah berbeda. Disebutkan secara ma'rifah (zakat harta) sebanyak 30 kali. 8 kali diantaranya terdapat dalam surah makkiyyah dan 22 kali terdapat dalam madaniyyah. Kemudian 28 ayat berhubungan dengan kewajiban menunaikan sholat. Ini menjadikan kedudukan zakat yang cukup tinggi dan penting dalam syari'at Islam. Zakat juga dapat mempererat hubungan mustahiq dan muzakki, meeningkatkan ukhuwah islamiyyah dan mengurangi angka kemiskinan (Sayyid Sabiq, 1968).

Al-Qur'an juga menyatakan bahwa zakat merupakan sebagai indikator utama kepatuhan seseorang terhadap ajaran Islam, yang akan mendapatkan kebahagiaan hidup, mendapatkan rahmat dan pertolongan Allah SWT (QS. alTawbah: 73 dan QS. al-Hajj: 40-41). Seseorang yang memenuhi kewajiban berzakat adalah yang berkeinginan untuk membersihkan diri dan jiwanya dari berbagai sifat buruk, seperti mementingkan diri sendiri, tamak dan sekaligus berkeinginan untuk selalu membersihkan, mensucikan dan mengembangkan harta yang dimilikinya (QS. alTawbah: 103 dan QS. al-Rūm: 39).

Orang-orang yang berhak memperoleh zakat terdiri dari delapan golongan, yaitu:

1. Fakir, yaitu orang yang tidak mempunyai apaapa atau tidak dapat memenuhi separuh dari kebutuhan cukupnya.

2. Miskin, yaitu orang dapat memenuhi separuh kebutuhan cukupnya atau lebih.

3. Amil, yaitu orang yang diangkat untuk mengurus zakat.

4. Muallaf, yaitu orang yang baru masuk islam sedangkan imannya teguh.

5. Budak, yaitu hamba yang telah dijanjikan tuannya bahwa dia boleh menebus dirinya dengan uang atau harta lainnya.

6. Gharimin, yaitu orang-orang yang mempunyai hutang, orang-orang yang memikul beban hutang untuk memperbaiki hubungan sesama manusia atau untuk memenuhi kebutuhankebutuhan pribadi mereka baik mereka miskin maupun kaya.

7. Fisabilillah, yaitu jihad dan segala sesuatu yang dibutuhkan dengan harus ada aktifitas jihad, seperti perekrutan pasukan perang, pendirian pabrik-pabrik dan industri senjata dan sebagainya.

8. Ibnu sabil, yaitu segala mereka yang kehabisan belanja dalam perjalanan dan tidak dapat mendatangkan belanjanya dari kampungnya, walaupun ia orang yang berharta di kampungnya. 


\subsection{Pengertian Kualitas Pelayanan}

Kualitas pelayanan adalah seberapa jauh perbedaan antara kenyataan dan harapan para pelanggan atas layanan yang mereka terima. Kualitas pelayanan dapat diketahui dengan cara membandingkan persepsi para pelanggan atas layanan yang benar-benar mereka terima (Tjiptono, 2001).

\subsection{Importance Performance Analysis (IPA)}

Metode Importance Performance Analysis (IPA) pertama kali diperkenalkan oleh Martilla dan James (1977) dengan tujuan untuk mengukur hubungan antara persepsi mustahiq dan prioritas peningkatan kualitas produk/jasa yang dikenal pula dengan quadrant analysis. Importance Performance Analysis (IPA) telah diterima secara umum dan dipergunakan pada berbagai bidang kajian karena kemudahan untuk diterapkan dan tampilan hasil analisa yang memudahkan usulan perbaikan kinerja.

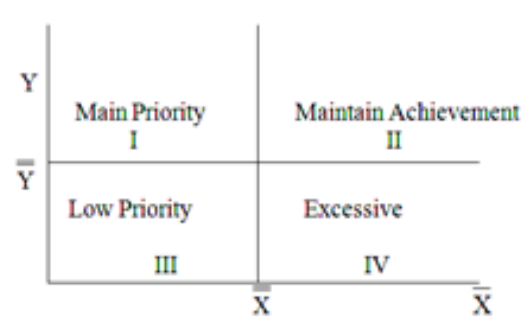

Gambar 1 Diagram kartesius Importance Performance Analysis (IPA)

Gambar 1 merupakan matriks IPA di mana terdapat empat kuadran untuk menganalisa kepentingan kinerja. Di bawah ini adalah penjelasan untuk masing-masing kuadran (Supranto, 2006).

1. Kuadran I (Prioritas Utama)

Dalam kuadran pertama ini adalah wilayah yang memuat faktor-faktor yang dianggap penting oleh pelanggan tetapi tingkat kepuasan yang diperoleh masih rendah.

2. Kuadran II (Pertahankan Prestasi)

Dalam kuadran kedua ini adalah wilayah yang memuat faktor-faktor yang dianggap penting oleh pelanggan dan faktor-faktor yang dirasakan relatif tinggi.

3. Kuadran III (Prioritas Rendah)

Dalam kuadran ketiga ini adalah wilayah yang memuat faktor-faktor yang dianggap kurang penting oleh pelanggan dan pada kenyataannya kinerjanya tidak terlalu istimewa. Karena manfaat yang dirasakan pelanggan sangat kecil.
4. Kuadran IV (Berlebihan)

Dalam kuadran ini wilayah yang memuat faktor-faktor yang dianggap kurang penting oleh pelanggan dan dirasakan terlalu berlebihan. Maka dari itu yang termasuk ke dalam kuadran ini dapat dikurangi agar perusahaan dapat menghemat biaya.

Tahapan dalam metode Importance Performance Analysis (IPA) adalah berikut :

a. Menentukan tingkat kesesuaian

$$
\mathrm{Tk}_{\mathrm{i}}=\frac{\mathrm{K}_{\mathrm{i}}}{\mathrm{H}_{\mathrm{i}}} \times 100 \%
$$

b. Menghitung rata-rata untuk setiap atribut

$$
\begin{aligned}
& \overline{X_{i}}=\frac{\sum X_{i}}{n} \\
& \overline{Y_{i}}=\frac{\sum Y_{i}}{n}
\end{aligned}
$$

c. Menghitung rata-rata seluruh atribut tingkat kepentingan $\overline{\bar{Y}}$ dan kinerja $\overline{\bar{X}}$ yang menjadi batas pada diagram kartesius.

$$
\begin{aligned}
& \overline{\bar{X}}=\frac{\sum \overline{X_{i}}}{k} \\
& \overline{\bar{Y}}=\frac{\sum \overline{Y_{i}}}{k}
\end{aligned}
$$

d. Melakukan pemetaan ke dalam diagram kartesius.

\section{METODE}

Metode dalam penyelesaian masalah dalam penelitian ini dilakukan dengan studi lapangan terhadap kasus kepuasan konsumen pada Baitul Mal kota Lhokseumawe. Adapun tahap-tahap yang dilakukan :

1. Melalui wawancara kepada mustahiq yang menjadi responden dengan menggunakan kuesioner.

2. Pengambilan sampel dilakukan dengan teknik pengambilan sampel non-acak yaitu prosedur memilih sampel berdasarkan pertimbangan karakteristik tertentu yang cocok dan diperlukan untuk menjawab penelitian.

3. Menentukan Karakteristik responden, responden yang diambil dalam penelitian ini adalah mustahiq fakir yaitu sebanyak 87 responden. pengambilan sampel menggunakan 
rumus Slovin di mana tingkat kepercayaan $90 \%$ dan tingkat kesalahan $10 \%$.

4. Menggunakan Metode Importance Performance Analysis (IPA) dan Model Kano untuk menganalisa kinerja Baitul Mal kota Lhoseumawe, serta menentukan kesimpulan dari hasil analisa.

\section{HASIL PENELITIAN}

Penelitian dilakukan di Baitul Mal di Kota Lhokseumawe. Dari hasil penelitian, penyebaran kuesioner dengan jumlah responden berdasarkan rumus metode slovin dimana tingkat kepercayaan 90\% dan tingkat kesalahan $10 \%$ uji Validitas dan Reliabilitas yang dilakukan, diketahui semua atribut dinyatakan valid dan reliable sehingga data dapat digunakan sebagai instrument penelitian. Untuk rata-rata tingkat kinerja dan tingkat kepentingan setiap atribut dapat dilihat pada Tabel 1.

\section{Metode Importance Performance Analysis (IPA)}

Tabel 1 Hasil perhitungan tingkat kesesuaian

\begin{tabular}{|c|c|c|c|c|}
\hline Atribut & $\begin{array}{c}\text { Skor } \\
\text { Kinerja } \\
\left(\mathbf{K}_{\mathbf{~}}\right)\end{array}$ & $\begin{array}{c}\text { Skor } \\
\text { Kepentingan } \\
\left(\mathbf{H}_{\mathbf{j}}\right)\end{array}$ & $\begin{array}{c}\text { Tingkat } \\
\text { Kinerja }\end{array}$ & $\begin{array}{c}\text { Tingkat } \\
\text { Kepentingan }\end{array}$ \\
\hline TAN1 & 345 & 349 & 3,97 & 4,01 \\
\hline TAN2 & 362 & 345 & 4,16 & 3,97 \\
\hline TAN3 & 349 & 360 & 4,01 & 4,14 \\
\hline TAN4 & 334 & 362 & 3,84 & 4,16 \\
\hline TAN5 & 350 & 359 & 4,02 & 4,13 \\
\hline TAN6 & 355 & 372 & 4,08 & 4,28 \\
\hline REL7 & 312 & 352 & 3,59 & 4,05 \\
\hline REL8 & 354 & 337 & 4,07 & 3,87 \\
\hline REL9 & 353 & 332 & 4,06 & 3,82 \\
\hline REL10 & 351 & 352 & 4,03 & 4,05 \\
\hline REL11 & 360 & 346 & 4,14 & 3,98 \\
\hline REL12 & 307 & 343 & 3,53 & 3,94 \\
\hline REL13 & 290 & 344 & 3,33 & 3,95 \\
\hline ASS14 & 282 & 345 & 3,24 & 3,97 \\
\hline ASS15 & 329 & 356 & 3,78 & 4,09 \\
\hline ASS16 & 322 & 352 & 3,70 & 4,05 \\
\hline ASS17 & 355 & 355 & 4,08 & 4,08 \\
\hline ASS18 & 289 & 348 & 3,32 & 4,00 \\
\hline ASS19 & 291 & 353 & 3,34 & 4,06 \\
\hline EMP20 & 313 & 347 & 3,60 & 3,99 \\
\hline EMP21 & 350 & 349 & 4,02 & 4,01 \\
\hline EMP22 & 335 & 334 & 3,85 & 3,84 \\
\hline EMP23 & 307 & 332 & 3,53 & 3,82 \\
\hline EMP24 & 304 & 323 & 3,49 & 3,71 \\
\hline & Average & $\mathbf{3 , 8}$ & $\mathbf{4 , 0}$ \\
\hline
\end{tabular}

Untuk gambar diagram kartesius Importance Performance Analysis (IPA) dapat dilihat pada Gambar 2.

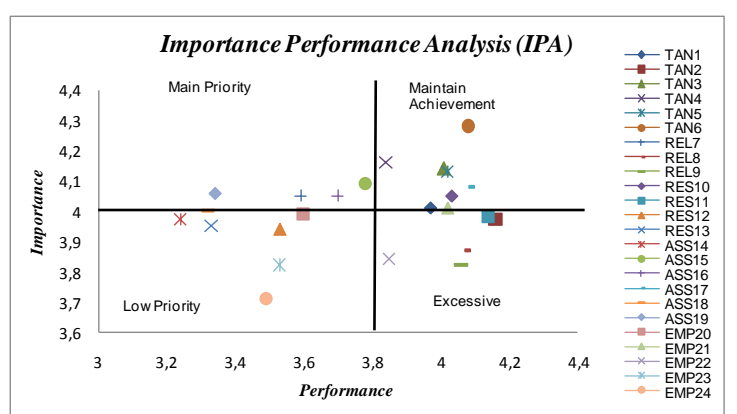

Gambar 2 Diagram Importance Performance Analysis (IPA)
Atribut-atribut yang termasuk dalam kuadran prioritas utama yaitu atribut yang dianggap penting tetapi kinerjanya masih dianggap kurang yaitu dapat dilihat pada Tabel 2.

Tabel 2 Atribut pelayanan yang termasuk dalam kategori prioritas utama

\begin{tabular}{|c|c|l|}
\hline Dimensi & \multicolumn{1}{|c|}{$\begin{array}{c}\text { Kode } \\
\text { Atribut }\end{array}$} & \multicolumn{1}{c|}{ Pertanyaan } \\
\hline \multirow{4}{*}{ Reliability } & REL7 & $\begin{array}{l}\text { Amil Baitul Mal Kota Lhokseumawe } \\
\text { menyelesaikan masalah mustahiq } \\
\text { terkait program zakat tepat waktu }\end{array}$ \\
\cline { 2 - 3 } & ASS15 & $\begin{array}{l}\text { Amil Baitul Mal Kota Lhokseumawe } \\
\text { dapat menjelaskan informasi kepada } \\
\text { mustahiq dengan jelas }\end{array}$ \\
\hline \multirow{5}{*}{ Assurance } & ASS16 & $\begin{array}{l}\text { Amil Baitul Mal Kota Lhokseumawe } \\
\text { memiliki pengetahuan tentang zakat }\end{array}$ \\
\cline { 2 - 3 } & ASS18 & $\begin{array}{l}\text { Zakat yang diberikan Baitul Mal kota } \\
\text { Lhokseumawe telah memenuhi } \\
\text { kebutuhan pokok mustahiq }\end{array}$ \\
\cline { 2 - 3 } & ASS19 & $\begin{array}{l}\text { Zakat yang diberikan Baitul Mal kota } \\
\text { Lhokseumawe mampu meningkatkan } \\
\text { kesejahteraan mustahiq }\end{array}$ \\
\hline
\end{tabular}

Atribut pelayanan Baitul Mal yang termasuk dalam kategori pertahankan prestasi dan harus dipertahankan kinerjanya karena sesuai dengan keinginan mustahiq yaitu dapat dilihat pada Tabel 3.

Tabel 3 Atribut pelayanan yang termasuk dalam kategori pertahankan prestasi

\begin{tabular}{|c|c|c|}
\hline Dimensi & $\begin{array}{c}\text { Kode } \\
\text { Atribut }\end{array}$ & Pertanyaan \\
\hline \multirow{5}{*}{ Tangible } & TAN1 & $\begin{array}{l}\text { Baitul Mal Kota Lhokseumawe } \\
\text { memiliki gedung yang memadai }\end{array}$ \\
\hline & TAN3 & $\begin{array}{l}\text { Baitul Mal Kota Lhokseumawe } \\
\text { memiliki gedung yang bersih }\end{array}$ \\
\hline & TAN4 & $\begin{array}{llr}\text { Amil Baitul Mal Kota } \\
\begin{array}{l}\text { Lhokseumawe } \\
\text { akhlak yang islami }\end{array}\end{array}$ \\
\hline & TAN5 & $\begin{array}{l}\text { Baitul Mal Kota Lhokseumawe } \\
\text { memiliki gedung yang rapi }\end{array}$ \\
\hline & TAN6 & $\begin{array}{l}\text { Baitul Mal Kota Lhokseumawe } \\
\text { memiliki ruang pelayanan yang } \\
\text { sesuai dengan fungsinya }\end{array}$ \\
\hline Responsivness & RES10 & $\begin{array}{l}\text { Baitul Mal Kota Lhokseumawe } \\
\text { selalu melayani mustahiq } \\
\text { dengan cepat }\end{array}$ \\
\hline Assurance & ASS17 & $\begin{array}{l}\text { Baitul Mal Kota Lhokseumawe } \\
\text { memiliki amil yang cukup, } \\
\text { sehingga selalu ada pengganti } \\
\text { jika ada yang berhalangan hadir }\end{array}$ \\
\hline Emphaty & EMP21 & $\begin{array}{l}\text { Amil Baitul Mal Kota } \\
\text { Lhokseumawe tidak membeda- } \\
\text { bedakan antara mustahiq yang } \\
\text { satu dengan yang lainnya }\end{array}$ \\
\hline
\end{tabular}

Atribut pelayanan Baitul Mal yang termasuk dalam kategori prioritas rendah dengan tingkat kepentingan rendah dan kenyataannya kinerjanya tidak terlalu istimewa dengan tingkat kepuasan yang rendah pula yaitu dapat dilihat pada Tabel 4 . 
Tabel 4 Atribut pelayanan yang termasuk dalam kategori prioritas rendah

\begin{tabular}{|c|c|c|}
\hline Dimensi & $\begin{array}{c}\text { Kode } \\
\text { Atribut }\end{array}$ & Pertanyaan \\
\hline \multirow[t]{2}{*}{ Responsivness } & RES12 & 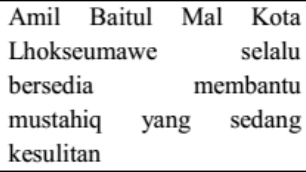 \\
\hline & RES13 & $\begin{array}{lrr}\text { Amil Baitul } & \text { Mal } & \text { Kota } \\
\text { Lhokseumawe } & & \text { selalu } \\
\text { mendengarkan } & & \text { keluhan } \\
\text { mustahiq } & & \\
\end{array}$ \\
\hline Assurance & ASS14 & $\begin{array}{l}\text { Amil Baitul Mal } \begin{array}{r}\text { Kota } \\
\text { Lhokseumawe }\end{array} \\
\text { menjelaskan } \\
\begin{array}{l}\text { kepada mustahiq dengan } \\
\text { detail }\end{array} \\
\end{array}$ \\
\hline \multirow{3}{*}{ Emphaty } & EMP20 & 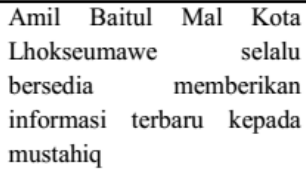 \\
\hline & EMP23 & 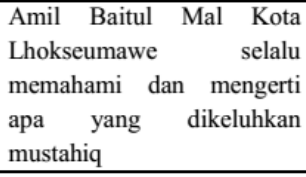 \\
\hline & EMP24 & $\begin{array}{lrr}\text { Amil Baitul } & \text { Mal } & \text { Kota } \\
\text { Lhokseumawe } & \text { selalu } \\
\text { memahami dan } & \text { mengerti } \\
\text { apa yang } & \text { diinginkan } \\
\text { mustahiq } & \\
\end{array}$ \\
\hline
\end{tabular}

Atribut pelayanan Baitul Mal yang termasuk dalam kategori berlebihan dengan tingkat kepentingan rendah dan dirasakan mustahiq terlalu berlebihan yaitu dapat dilihat pada Tabel 5.

Tabel 5 Atribut pelayanan yang termasuk dalam kategori berlebihan

\begin{tabular}{|c|c|l|}
\hline Dimensi & $\begin{array}{c}\text { Kode } \\
\text { Atribut }\end{array}$ & \multicolumn{1}{c|}{ Pertanyaan } \\
\hline Tangible & TAN2 & $\begin{array}{l}\text { Baitul Mal Kota } \\
\text { Lhokseumawe memiliki } \\
\text { gedung yang nyaman }\end{array}$ \\
\hline \multirow{5}{*}{ Reliability } & REL9 & $\begin{array}{l}\text { Amil Baitul Mal Kota } \\
\text { Lhokseumawe selalu ada di } \\
\text { dalam kantor ketika jam } \\
\text { kerja }\end{array}$ \\
\cline { 2 - 4 } & REL11 & $\begin{array}{l}\text { Baitul Mal Kota } \\
\text { Lhokseumawe memiliki } \\
\text { prosedur pendaftaran yang } \\
\text { mudah untuk menjadi } \\
\text { mustahiq }\end{array}$ \\
\cline { 2 - 4 } Emphaty & EMP22 & $\begin{array}{l}\text { Amil Baitul Mal Kota } \\
\text { Lhokseumawe dapat } \\
\text { menjawab pertanyaan yang } \\
\text { diajukan oleh mustahiq }\end{array}$ \\
\hline & $\begin{array}{l}\text { Amil Baitul Mal Kota } \\
\text { Lhokseumawe selalu } \\
\text { bersedia membantu } \\
\text { mustahiq yang sedang } \\
\text { kesulitan }\end{array}$ \\
\hline
\end{tabular}

\section{KESIMPULAN}

Berdasarkan hasil dan pembahasan yang telah dilakukan, maka dapat diperoleh kesimpulan:

1. Atribut-atribut pelayanan dalam prioritas utama yang dianggap penting tetapi kinerjanya masih kurang memuaskan bagi penerima zakat (mustahiq) serta perlu untuk diperhatikan oleh pihak Baitul Mal untuk menjaga mustahiqnya agar tetap dapat meningkatkan kesejahteraan.

2. Mustahiq adalah Amil Baitul Mal Kota Lhokseumawe

3. Penyelesaian masalah mustahiq yang menjadi prioritas terkait program zakat tepat waktu (REL7), Amil Baitul Mal Kota Lhokseumawe dapat menjelaskan informasi kepada mustahiq dengan jelas (ASS15), Amil Baitul Mal Kota Lhokseumawe memiliki pengetahuan tentang zakat (ASS16), Zakat yang diberikan Baitul Mal kota Lhokseumawe telah memenuhi kebutuhan pokok mustahiq (ASS18), dan Zakat yang diberikan Baitul Mal kota Lhokseumawe mampu meningkatkan kesejahteraan mustahiq (ASS19).

\section{SARAN}

Berdasarkan penelitian yang telah dilakukan, maka penulis memberikan saran sebagai berikut:

1. Diharapkan pihak Amil Baitul Mal dapat meningkatkan kinerja atribut pelayanannya berdasarkan harapan dari Mustahiq.

2. Penelitian ini dapat dilanjutkan dengan menganalisis faktor-faktor penyebab rendahnya beberapa kinerja atribut pelayanan yang penting, sehingga peningkatan kualitas pelayanan Baitul Mal dapat dikedepankan sebagai sektor publik.

\section{DAFTAR PUSTAKA}

Ali Yafie (1994). Menggagas Fiqh Sosial. Bandung: Mizan, h. 231.

http://eprints.dinus.ac.id/8558/1/jurnal_11864.pdf http://skripsitipftp.staff.ub.ac.id/files/2014/10/JU RNAL-Heru-Eka-Lodhita.pdf

http://industria.ub.ac.id/index.php/industri/article/ download/179/184

Majma Lughah al-'Arabiyyah (1972). alMu’jām al-Wasịt. Misr: Dār al-Ma'ārif. juz 1 h. 396.

Mulyani, 2008. Analisis Sistem Laporan dana ZIS Pada Baitul Maal Muamalat (BMM) Jogjakarta. Jurnal Dinamika Ekonomi \& Bisnis Vol 5 No 2.

QS. al-Tawbah: 73 dan QS. al-Hajj: 40-41 
QS. al-Tawbah: 103 dan QS. al-Rūm: 39. Baca Al-Qurțubī (1993), al-Jāmi’ li Ahkām alQurān, Bayrut: Dār al-Kutūb al-'Ilmiyyah, h. 156 .

Sayyid Sabiq (1968). op.cit., h. 5. Lihat juga Yūsuf Qaraḍāwī (1985). op.cit., h. 44. Hasbi As-Siddiqy (2006), op.cit., h. 4-5.

Supranto, J. 2006. Pengukuran tingkat kepuasan pelanggan. Cetakan ketiga. PT. RIN CIPTA. Jakarta.

Tjiptono, F. 2001. Strategi Pemasaran. Andi Offset. Yogyakarta

Yūsuf Qaraḍāwī (1993). Al-'Ibādah Fī al-Islām. Bayrut: Muassasah al-Risālah. h. 235. 